\title{
STUDIES ON THE TOXIC INTERACTION BETWEEN MONENSIN AND TIAMULIN IN RATS: EFFECTS ON P450 ACTIVITIES
}

\author{
G. SzÜCS ${ }^{1 *}$, P. LACZAY ${ }^{2}$, Judit BAJNÓGEL ${ }^{1}$ and Zsuzsa MóRA ${ }^{2}$ \\ ${ }^{1}$ Department of Toxicology, EGIS Pharmaceuticals Ltd, H-1475 Budapest 10, \\ P.O. Box 100, Hungary; ${ }^{2}$ Department of Pharmacology and Toxicology, Faculty of \\ Veterinary Science, Szent István University, H-1400 Budapest, P.O. Box 2, Hungary
}

(Received October 7, 1999; accepted February 1, 2000)

\begin{abstract}
Studies were carried out to investigate the effects of monensin and tiamulin, and the simultaneous administration of both compounds on microsomal enzymes in rats. In Phase I of the experiments the effects of monensin and tiamulin were studied separately (monensin 10,30, and $50 \mathrm{mg} / \mathrm{kg}$ or tiamulin 40,120 , and $200 \mathrm{mg} / \mathrm{kg}$ body weight, respectively), while in Phase II the two compounds were administered simultaneously (monensin $10 \mathrm{mg} / \mathrm{kg}$ and tiamulin $40 \mathrm{mg} / \mathrm{kg}$ b.w., respectively). When monensin was administered by itself, it exerted no significant effect on microsomal liver enzymes. In a few cases, slight inhibition of certain enzyme activities was seen. Tiamulin provoked a dose-dependent hepatic enzyme induction. The combined administration of monensin and tiamulin at low doses (10 and $40 \mathrm{mg} / \mathrm{kg}$, respectively) resulted in marked elevation of P450-related enzyme activities. The enzyme induction was more pronounced in females than in males. The results suggest that the simultaneous administration of tiamulin may influence the biotransformation of monensin, possibly increasing the amount of reactive metabolite(s) of the ionophore antibiotic.
\end{abstract}

Key words: Ionophore, monensin, tiamulin, comparative toxicity, toxic interaction, enzyme induction, rats

The pathogenic mechanisms of the interactions between monensin and tiamulin are not clearly understood. It has been suggested that the toxic interactions are either caused by accumulation of the ionophores in the body, because of an inhibition of their oxidative biotransformation by tiamulin (Meingasser et al., 1979; Anadón et al., 1989) or are generated by an increase in the formation rate of reactive metabolites of the ionophores, resulting from an induction of the metabolising enzymes by the pleuromutilin derivative (Laczay et al., 1990).

Recently, Witkamp et al. $(1994,1995)$ found a strong inhibition of the microsomal N-demethylation of ethylmorphine and the hydroxylation of testosterone at the $6 \beta$-position by tiamulin in vitro using pig liver microsomes and cul-

\footnotetext{
*E-mail: hatastan@mail.datanet.hu; Fax: +36 (1) 404-4888
} 
tured primary hepatocytes, and postulated a selective inhibition of cytochrome P450 enzymes in pigs, likely belonging to the P4503A subfamily.

A series of experiments were performed in rats to study the repeated-dose toxicity of monensin, tiamulin, and the combined administration of both substances as well as to investigate their effects on the microsomal enzymes of the liver. The results of the toxicity studies were reported previously (Szücs et al., 2000). In the present paper the findings on drug-metabolising enzymes are summarised.

\section{Materials and methods}

Animals. Crl:(WI)BR rats (supplier: SPF Animal House of EGIS Pharmaceuticals Ltd., H-1165 Budapest, Hungary), 5 weeks of age upon receipt, were used in both phases of the experiment. Housing conditions and feeding of the animals were the same as described in our previous paper (Szücs et al., 2000).

Compounds. Monensin, sodium salt (Sigma); tiamulin fumarate (Dynamutulin, Novartis).

Vehicle. Methylcellulose (Hungaropharma) and distilled water (EGIS).

Experimental design and treatments. In Phase I, the effects of monensin and tiamulin were studied separately. Approximately 6 weeks old Wistar rats ( 5 animals per sex) were treated on three consecutive days with monensin at dose levels of 10,30 and $50 \mathrm{mg} / \mathrm{kg}$, or with tiamulin at 40,120 and $200 \mathrm{mg} / \mathrm{kg}$. In Phase II, the two compounds were administered simultaneously. Rats of the same strain, breeder and age (10 animals per sex) were treated by the oral route for three consecutive days with monensin $10 \mathrm{mg} / \mathrm{kg}$ and tiamulin $40 \mathrm{mg} / \mathrm{kg}$, respectively. Vehicle-treated (1\% methylcellulose suspension, treatment volume: $10 \mathrm{ml} / \mathrm{kg})$ control groups ( 5 rats per sex) were included in both phases of the study.

Parameters examined (Phase I and Phase II) : In order to study the effects of the substances investigated on the drug-metabolising enzymes, the following parameters were measured: microsomal protein, cytochrome P-450 (Cyt. P-450), cytochrome $b_{5}\left(\right.$ Cyt. $\left.b_{5}\right)$, NADPH cytochrome c reductase (Cyt. c red.), benzopyrene hydroxylase (AHH), aniline-p-hydroxylase (p-hydr.), aminopyrine N-demethylase (N-dem. a.), ethylmorphine $\mathrm{N}$-demethylase (N-dem. em.), p-nitroanisol O-demethylase (O-dem.), ethoxyresorufin O-deethylase (EROD), ethoxycoumarin Odeethylase (ECOD), epoxide hydratase (EPH), and liver weights.

Cytochrome P-450 and microsomal enzyme assays. At $24 \mathrm{~h}$ post-treatment, all rats were killed by exsanguination under ether anaesthesia. The livers were rapidly removed and weighed and a sample of approximately $2 \mathrm{~g}$ (cut always from the same lobule) was put in ice-cold physiologic saline solution. The liver samples were minced and homogenised. The homogenate was centrifuged at 10,000 then at $100,000 \mathrm{~g}$ and the microsomal fractions were stored at $-70{ }^{\circ} \mathrm{C}$ until examination. Microsomal protein, Cyt. P450 and Cyt. $\mathrm{B}_{5}$ concentrations as 
well as the enzyme activities were determined by standard methods. A Beckman spectrophotometer and a Hewlett-Packard liquid scintillator were used for the measurements.

Statistical analyses were the same as described in the previous paper (Szücs et al., 2000).

\section{Results}

\section{PHASE I}

Microsomal enzymes. No effect was observed on microsomal enzymes in the case of monensin treatment. Most enzymes remained at control levels or a slight inhibition was observed. Aminopyrine N-demethylase activity decreased $(-26 \%)$ in males and epoxide hydratase activity decreased significantly $(-31 \%)$ in females $(\mathrm{p}<0.01)$.

Tiamulin elicited dose-dependent enzyme induction. Statistical significance $(\mathrm{p}<0.01)$ was reached in several parameters in the 120 and $200 \mathrm{mg} / \mathrm{kg}$ treated dose groups. Total cytochrome P-450 activity increased by 46 and $121 \%$ in males and 86 and $202 \%$ in females, respectively. Cytochrome $b_{5}$ activity increased by 23 and $59 \%$ in males and 38 and $83 \%$ in females, respectively. A similar trend was observed for ethylmorphine N-demethylase activity (13 and $40 \%$ increase in males and 191 and $262 \%$ in females, respectively). Surprisingly, aminopyrine $\mathrm{N}$-demethylase activity was inhibited in a dose-dependent manner in males $(-22,-36$ and $-30 \%$ decrease, respectively) and there was no significant effect relating to this parameter in females.

Benzopyrene hydroxylase activity was significantly induced $(\mathrm{p}<0.01)$ in males $(140 \%)$ as well as epoxide hydratase in females (34\%) (Table 1).

Organ weight measurement. A moderate increase (19\%) was seen in liver weights in the females treated with tiamulin showing some dose-dependent tendency, but the alteration proved to be significant $(\mathrm{p}<0.05)$ only in the animals treated with the $200 \mathrm{mg} / \mathrm{kg}$ dose (Table 2).

\section{PHASE II}

Microsomal enzymes. Compared to the administered dose, a more pronounced enzyme induction was observed in Phase II than in Phase I, when aniline-p-hydroxylase ( $38 \%$ and $112 \%$, respectively) and benzopyrene hydroxylase $(28 \%$ and $29 \%$, respectively) activity increased (statistical significance: $p<0.01$ ) in both sexes. Cytochrome c reductase increased moderately in males $(36 \%, \mathrm{p}<$ $0.01)$ and cytochrome P-450 activity in females $(28 \%, \mathrm{p}<0.01)$. Like induction, inhibition of epoxide hydratase $(-23 \%$ and $-31 \%$, respectively, $\mathrm{p}<0.01)$ was also registered in both sexes. Aminopyrine N-demethylase was inhibited (-23\%, $\mathrm{p}<0.01$ ) only in males (Table 3 ). 


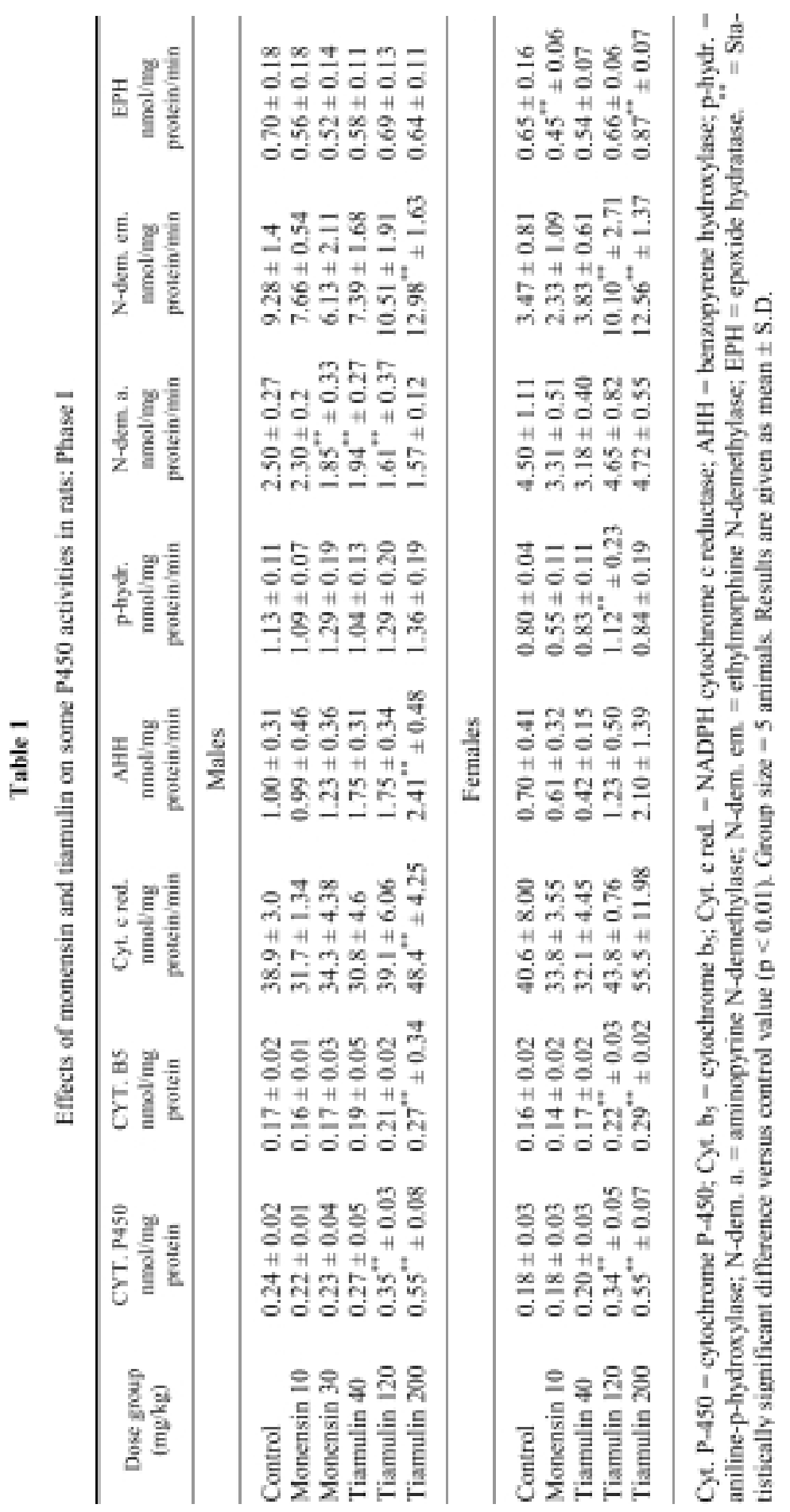




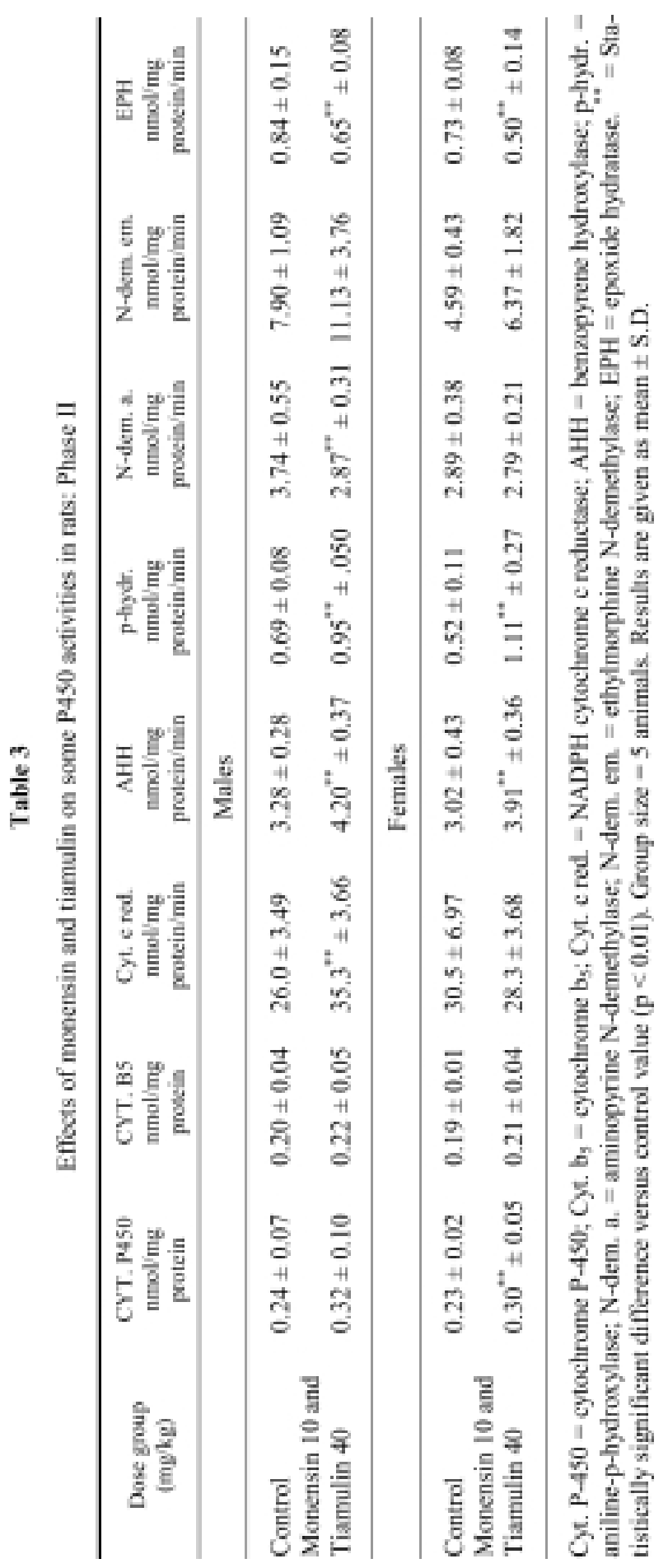


Table 2

Changes in absolute and body weight relative liver weights (g): Phase I

\begin{tabular}{lccccc}
\hline \multirow{2}{*}{$\begin{array}{c}\text { Dose-group } \\
(\mathrm{mg} / \mathrm{kg})\end{array}$} & \multicolumn{2}{c}{ Males } & \multicolumn{2}{c}{ Females } \\
\cline { 2 - 3 } \cline { 5 - 6 } & Absolute & Relative & & Absolute & Relative \\
\hline Control & $6.04 \pm 0.22$ & $3.70 \pm 0.12$ & & $4.96 \pm 0.50$ & $3.53 \pm 0.16$ \\
Monensin 10 & $5.65 \pm 0.37$ & $3.38 \pm 0.34$ & & $4.98 \pm 0.53$ & $3.84 \pm 0.73$ \\
Monensin 30 & $5.91 \pm 0.56$ & $3.61 \pm 0.21$ & & NI & NI \\
Tiamulin 40 & $6.16 \pm 0.71$ & $3.67 \pm 0.25$ & & $5.147 \pm 0.42$ & $3.52 \pm 0.24$ \\
Tiamulin 120 & $6.25 \pm 0.61$ & $3.65 \pm 0.17$ & & $5.55 \pm 0.25$ & $3.82 \pm 0.12$ \\
Tiamulin 200 & $6.16 \pm 0.60$ & $3.77 \pm 0.38$ & & $5.90^{*} \pm 0.55$ & $3.99 \pm 0.22$ \\
\hline
\end{tabular}

* = Statistically significant difference versus control value $(\mathrm{p}<0.05)$. Group size $(\mathrm{n})=5$ animals. $\mathrm{NI}=$ Not investigated $(\mathrm{n}<3$ animals). Results are given as mean \pm S.D.

Organ weight measurement. Examination of absolute and body weight relative organ weights did not reveal any treatment-related effects. There was no associated increase in liver weight with the observed enzyme induction.

\section{Discussion}

Monensin proved to be toxic to rats at doses of 30 and $50 \mathrm{mg} / \mathrm{kg}$. Tiamulin was well tolerated up to the dose of $200 \mathrm{mg} / \mathrm{kg}$. The maximum tolerated dose of monensin $(10 \mathrm{mg} / \mathrm{kg})$ and the non-toxic dose of tiamulin $(40 \mathrm{mg} / \mathrm{kg})$ were administered simultaneously in Phase II. A slight increase, showing some dosedependent tendency, was seen in liver weights in the females treated with tiamulin. There were no significant changes in liver weights in males and in the monensin-treated animals or after the combined treatment with monensin and tiamulin in both sexes. Monensin exerted no effect on microsomal liver enzymes or elicited slight inhibition of enzyme activity (aminopyrine N-demethylase in males and epoxide hydratase activity in females). Tiamulin elicited a dosedependent induction of total P450 activity in both sexes. The combined administration of monensin and tiamulin at relatively low doses $(10$ and $40 \mathrm{mg} / \mathrm{kg}$, respectively) resulted in a considerable elevation of P450 activity. Ethylmorphine $\mathrm{N}$-demethylase activity was induced by tiamulin itself and after the combined administration of the two compounds as well. Aminopyrine N-demethylase activity decreased in males due to different dose levels of tiamulin and at the simultaneous administration of tiamulin and monensin. No significant changes were seen in females regarding this parameter. The differences in the effect on the two N-demethylases are not understood. It might be explained by the postulated selective inducer-inhibitor effect of tiamulin. The enzyme induction was more pronounced in females than in males. The sex difference in sensitivity can 
be explained by the differences in P450 levels (relatively lower P450 levels in females than in males, the liver microsomal enzymes of which can be induced more markedly in females than in males).

In rats, tiamulin ( 40 and $226 \mathrm{mg} / \mathrm{kg}$ for 6 days) was reported to cause a dose-dependent complex formation as evidenced by its absorption spectrum, and an increase in cytochrome P-4503A1/2 contents as assessed by Western blotting (immunoblotting) was found. The effects were comparable to those of triacetyloleandromycin (TAO). Tiamulin induced microsomal P-450 content, testosterone $6 \beta$-hydroxylation rate, erythromycin N-demethylation rate, and ethoxyresorufin O-deethylation activity. Other activities were not affected or decreased. When tiamulin was added to microsomes of control rats, the testosterone 6 $\beta$-hydroxylation rate and the erythromycin $\mathrm{N}$-demethylation rate were strongly inhibited. It is concluded that tiamulin is a potent and selective inducer-inhibitor of cytochrome P-450. Though not belonging to macrolides, the compound produced an effect on P-450 similar to those of TAO and related compounds (Witkamp et al., 1994; Witkamp et al., 1995).

Results obtained from the present studies confirm that tiamulin may affect some cytochrome $\mathrm{P} 450$ mediated metabolic pathways in rats. The N-demethylation of ethylmorphine, which is mainly catalysed by enzymes of the P4503A subfamily in rats, mice and other mammals studied so far (Kamataki, 1993) was markedly increased by tiamulin in itself or due to the simultaneous administration of tiamulin and monensin. The combined administration of tiamulin and monensin resulted, however, in the induction of aniline-p-hydroxylase and benzopyrene hydroxylase activities which are catalysed by other P450 enzymes in rats. In chickens, tiamulin or the simultaneous administration of tiamulin and monensin also induced some microsomal activities, which in rats are associated with subfamilies other than P4503A (Rátz et al., 1997).

The present results are in good agreement with the findings in chickens, where it was seen that tiamulin is a potent inducer of certain P450 enzyme activities and also the combined application of tiamulin and monensin results in a marked induction of several microsomal activities (Laczay et al., 1990; Rátz et al., 1997).

In conclusion, the results obtained from the present studies in rats indicate a dose-dependent induction of some P450 mediated catalytic activities by tiamulin in this species as well. Monensin elicited slight inhibition of a few microsomal enzymes, whereas the combined administration of the two compounds was characterised mainly by enzyme induction. Not always the same type of enzymes was affected by the compounds alone or when they were given simultaneously, and there was a gender effect as well. Some enzymes were, however, inhibited at the combined administration (epoxide hydratase in both sexes and aminopyrine $\mathrm{N}$-demethylase in males), which can be an argument for a selective mode of metabolic induction and inhibition in rats. 
Data obtained in the present experiments may support the hypothesis that the toxic interaction between monensin and tiamulin might be due to the increased formation rate of a reactive metabolite(s) of monensin as a consequence of the inducing effect of tiamulin on some P450 mediated enzyme activities. The possible role of a metabolite of monensin in the toxic effect of the ionophore has also been suggested by others (Mollenhauer et al., 1990) based on differences in subcellular responses to monensin between the whole animal in vivo and isolated cells or organs in vitro.

Since the mechanism of the toxic interaction is still not perfectly understood, further investigations are needed to clarify the mechanism. Therefore, an ex vivo investigation on phenobarbital- and dexamethasone-induced microsomes is under evaluation.

\section{References}

Anadón, A., Martinez-Larrañaga, M. R., Diaz, M. J. and Bringas, P. (1989): Effect of tiamulin on antipyrine kinetics in chickens. J. Vet. Pharmacol. Therap. 12, 94-98.

Kamataki, T. (1993): Metabolism of xenobiotics. In: Omura, T., Ishimura, Y. and Fuji-Kurlyama, Y. (eds) Cytochrome P-450. 2nd ed, VCH Publisher Inc., New York, pp. 141-158.

Laczay, P., Simon, F. and Lehel, J. (1990): Investigations on the influence of monensin, tiamulin and of simultaneous application of both substances on the activities of the microsomal mixed function oxygenases and of the formation of peroxides in broilers. Dtsch. Tierärtzl. Wschr. 97, 354-357.

Meingasser, J. G., Schmook, F. P., Czok, R. and Mieth, H. (1979): Enhancement of the anticoccidial activity of polyether antibiotics in chickens by tiamulin. Poultry Sci. 58, 303-313.

Mollenhauer, H. H., Morre, J. D. and Rowe, L. D. (1990): Alteration of intracellular traffic by monensin; mechanism, specificity and relationship to toxicity. Biochem. Biophys. Acta 1031, $225-246$.

Rátz, V., Laczay, P., Móra, Zs., Csikó, Gy., Monostori, K., Vereczkey, L., Lehel, J. and Semjén, G. (1997): Recent studies on the effects of tiamulin and monensin on hepatic cytochrome P450 activities in chickens and turkeys. J. Vet. Pharmacol. Therap. 20, 1-4.

Szücs, G., Bajnógel, J., Varga, A., Móra, Zs. and Laczay, P. (2000): Studies on the toxic interaction between monensin and tiamulin in rats: Toxicity and pathology. Acta Vet. Hung. 48, 209-219.

Witkamp, R. F., Nijmeijer, S. M., Csikó, G. and van Miert, A. S. I. P. A. M. (1994): Tiamulin selectively inhibits oxidative hepatic steroid and drug metabolism in vitro in the pig. J. Vet. Pharmacol. Therap. 17, 317-322.

Witkamp, R. F., Nijmeijer, S. M., Monshouwer, M. and van Miert, A. S. I. P. A. M. (1995): The antibiotic tiamulin is a potent inducer and inhibitor of cytochrome P4503A via the formation of a stable metabolic intermediate complex. Drug Metab. Disp. 23, 542-547. 